\title{
The phenomenology and cognitive neuroscience of experienced temporality
}

\author{
Mauro Dorato $^{1} \cdot$ Marc Wittmann $^{2}$ \\ mauro.dorato@gmail.com \\ ${ }^{1}$ Department of Philosophy, Communication and Media Studies, Roma Tre University, Via \\ Ostiense, 234-236, 00146 Roma, Italy \\ ORCID: 0000-0002-8313-6362
}

${ }^{2}$ Institute for Frontier Areas of Psychology and Mental Health, Wilhelmstr. 3a, 70104 Freiburg,
Germany
ORCID: 0000-0002-4483-7334

\begin{abstract}
We discuss the three dominant models of the phenomenological literature pertaining to temporal consciousness, namely the cinematic, the retentional, and the extensional model. By relying on the distinction between acts and contents of consciousness we first discuss the explanatory merits of these three views vis à vis our temporal experience. In the second part of the paper, we review some relevant findings from the psychology and neuroscience of temporality in order to evaluate which of the three models of time consciousness is better confirmed from an empirical viewpoint. Depending on the time scale, all of the three models of temporal consciousness might be justified but we claim that the empirical evidence favours the extensional model, where the acts and contents of consciousness are both extended. The retentional model might apply to longer time intervals covered by working memory but, similarly to the cinematic model, it is open to the objection that from a neurophysiological point of view the brain processes which underlie acts of consciousness must necessarily be extended in time. We conclude by stressing a so-far neglected predictive component that is to be regarded as decisive for an understanding of our experience of temporality.
\end{abstract}

Keywords Cinematical model · Retentional model · Extensional model · Time consciousness $\cdot$ Time perception $\cdot$ Prediction 


\section{Introduction}

In the phenomenological literature on the experience of time it is customary to distinguish among three models (Roselli 2019), namely the cinematic model (Chuard 2011, Prosser 2016), the retentional model (Grush 2007, Kiverstein 2010, Pelczar 2010) and the extensional model (e.g. Dainton 2010a, 2010b, 2011, 2014, Hoerl 2009, 2013).

In this paper we try to situate the discussion of these three models within an empirical framework provided by the cognitive sciences. In particular, our aim is to evaluate whether findings in experimental neuropsychology are relevant or can even decide among these phenomenological models on an empirical basis, or, alternatively, whether such findings suggest a different phenomenological model that has not yet been considered. On the philosophical assumption that phenomenological models should not be regarded as autonomous from empirical research (Mölder 2014), we will claim that, depending on the time range involved, there is empirical evidence for the extensional model, in particular when this model is supplemented by an important prospective component which has often been neglected.

The paper is organized as follows. In its first part, we briefly review the three abovementioned models with the purpose of evaluating their explanatory power vis à vis our experience of time. In the second part we raise the question whether available empirical data may provide independent empirical evidence for one of these explanatory models. This issue will be discussed in the second section, where we discuss the empirical findings that we deem relevant to defend our main claim, namely that the extensional model seems better confirmed by the empirical evidence. In principle, the cinematic and the retentional model might be compatible with some relevant empirical data at different time scales: however, since any biological process takes time and in any empirical evaluation of the models it is indispensable to refer to underlying brain processes, we will conclude that an unextended act of consciousness as postulated by the cinematic and well by the retentional model is biologically and neurophysiogically implausible. The mechanistic basis of any act of consciousness necessitates of an interval of time (Longo \& Montévil 2011).

An initial motivation to the transition between the first and the second part is that, as a general methodological point, theories (in particular when they exemplify an equal degree of explanatory force) must be selected on the basis of their evidential strength. And even if we were in the position to conclude that a theory M explains the phenomenological data better than another theory M', it may still be the case that M' has more evidential empirical support: the world need not be simple or accountable by few powerful hypotheses. In the final section, we draw some general lessons on the relationship between phenomenological analyses of time 
consciousness and empirical sources of knowledge. The methodological approach that we favor can be summarized by adapting to our case the famous Kantian slogan: empirical data without phenomenological guidance are blind, but phenomenology without empirical evidence is empty. ${ }^{1}$ Obviously, this paper does not have the ambition to provide a final model of how the brain creates temporal experience and how this relates to phenomenological models of our temporal consciousness. Its interest, we submit, lies in the fact that, to our knowledge at least, only few attempts have been made to juxtapose insights from psychology and neuroscience with phenomenological models of our temporal experience.

\section{Three models of temporal consciousness}

In order to introduce the main three phenomenological models of time consciousness, it is useful to disentangle various terminological and conceptual questions that are relevant to characterize them. At least initially, it is useful to distinguish between the act of consciousness and what is represented by the act, its phenomenal content. Dainton spells out this distinction in terms of awareness and consciousness: "when we are conscious of a sound, we are aware of it: consciousness consists of an awareness of phenomenal contents: items such as sounds, colors, bodily sensations, thoughts and so on. Hence there is a distinction between phenomenal contents and acts of awareness." (Dainton, 2010a, p. 108; emphasis in the original). At this point two remarks are in order. In what follows, and by cutting short a lot of very difficult and complicated matters, we will follow Dainton by assuming that conscious states having as their content phenomena like change or motion are simply constituted by our awareness of them, in the sense that acts of awareness are a condition of possibility for having phenomenal content. ${ }^{2}$ The second remark is that while Dainton's quotation seems to presuppose a sense-data theory of perception, in which, as BonJour (2002, p. 122) has it, "the nature of immediate experience is accounted for by postulating both an act of awareness (or apprehension) and an object (the sense-datum) which that act apprehends or is an awareness of" (2002, p. 122). Here we will ignore this difficult question, namely, whether we are aware directly of properties of physical objects and events, including the temporal relations they exemplify - direct realism - or whether we represent a mind-independent physical world from certain unavoidable "perspectives" indirect realism.

\footnotetext{
${ }^{1}$ This slogan of course takes into due consideration the fact that phenomenological analyses in general cannot easily be regarded as based on purely a priori knowledge. After all, such analyses have as material the intentional content of our mental states. However, they can be regarded a priori in the sense that they bracket any data coming from physical time and mental time.

${ }^{2}$ Of course, we can perceive the tick-tack of an alarm clock without being aware of it, that is, without paying our conscious attention to it. But unconscious perceptions of these kinds will be simply left out of our paper.
} 
On this preliminary basis, and by taking for granted Dainton's distinction between acts and their phenomenal contents, in the literature it is customary to distinguish among three possible models of our experience of time, the cinematic, the retentional and the extensional model, all of them dependent on the aforementioned distinction between act and content. As a consequence, we can consistently distinguish among three different models of time experience: (i) Either both the conscious act and the content of consciousness are temporally unextended or "instantaneous" 3 , a view that is often referred to as the cinematic model, to which we will refer as $\left(\mathrm{M}_{1}\right)$ or (ii) the act is instantaneous but the content is not - this model is referred to as the retentional model $\left(\mathrm{M}_{2}\right)$; or (iii) both the act and the content have some finite duration (the extensional model or $\mathrm{M}_{3}$ ). These models are listed in the first three rows of Table 1 . In the fourth row, we added for completeness another possible model that is not contemplated in the literature, namely what we label the antiretentional model $\mathrm{M}_{4}$.

\section{Insert Table 1 about here}

Table 1. Phenomenological models of temporal consciousness characterized by acts and contents of consciousness as unextended or extended. The three models typically discussed are marked in bold.

\begin{tabular}{|l|l|l|}
\hline Models of temporal consciousness & Conscious Act & Content of the act \\
\hline Cinematic Model $\left(\mathbf{M}_{\mathbf{1}}\right)$ & Temporally Unextended & Temporally Unextended \\
\hline Retentional Model $\left(\mathbf{M}_{2}\right)$ & Temporally Unextended & Temporally Extended \\
\hline Extensional Model $\left(\mathbf{M}_{3}\right)$ & Temporally Extended & Temporally Extended \\
\hline Antiretentional Model $\left(\mathbf{M}_{4}\right)$ & Temporally Extended & Temporally Unextended \\
\hline
\end{tabular}

Given that in this section our purpose is only to evaluate their explanatory power vis a vis our temporal experience, our presentation of these models can afford to be brief. In particular, we will be invoking what philosophers call an inference to the best explanation which might allow us to conclude that we ought to favour the model(s) with the highest explanatory power,

\footnotetext{
${ }^{3}$ We choose the label "temporally unextended" in order to contrast it sharply with "temporally extended". In some cases, in the literature, "temporally unextended" in our context is spelled out in terms of "momentary (or extremely brief) states of consciousness" (Dainton 2011, p. 395), or in terms of states lacking any significant temporal extension (Dainton 2010a). Therefore, in what follows, and for the sake of clarity, we will treat any mention of "momentary" literally, and therefore as co-extensional with strictly unextended. Otherwise, given the vagueness of 'significant' referring to 'extension', we would water down the distinction between our models, unless we could devise an empirically established threshold above which we can say that the content or the act are "significantly" extended.
} 
where "highest" is determined by epistemic considerations involving the best balance between simplicity and scope of the explanation.

The cinematic model ought to explain the perception of continuous change and motion in our sensory field by supposing that at a fundamental level there is a rapid succession of temporally unextended contents registered by momentary acts of consciousness. How can an instantaneous content of our experience generate an experience of continuous passage? Is such an experience illusory? The explanatory task raised by this model would then consist in showing how the seamlessly changing contents of our temporal experience, -similar to snapshots or static frames of a movie, are fused together thanks to acts of consciousness each of which are themselves instantaneous. In a word, the cinematic model must suppose that a whole sequence of unextended phenomenal snapshots can in principle be explained by a corresponding series of momentary acts of awareness, in such a way as to generate the impression of a continuous succession or change in the content of momentary acts.

The second model present in the table above is the retentional model, which is based on the hypothesis that the immediate past is "retained" within an instantaneous act of consciousness, so that we are directly aware of a finitely extended temporal interval, within which retentions and retentions of retentions generate an impression of continuous motion and change. To exemplify, imagine a simplified model of an information gathering and utilizing system (IGUS as Hartle, 2005, originally named them) with a finite number of memory registers (for simplicity, say four, P1, P2, P3, P4), which are successively occupied by new experiences of present events. ${ }^{4}$ Suppose the first present experience is in P1. With the passage of time P2 is experienced in the present, but the content of P1 is retained in P2 with some continuity. When P3 is in its turn experienced in the present, the memory of P2 is retained in P3's register, but since within a certain duration on which we will expand later P2 still contains the memory contained in $\mathrm{P} 1$, the contents of the latter register are still affecting the present experience contained in P3. Finally, when P4 is experienced, P3 is retained together with its memory contents $\mathrm{P} 2$ and $\mathrm{P} 1$. In the meantime, the organism experiences new events with the same registers and the memory contained in $\mathrm{P} 4$ fades even more. ${ }^{5}$

The third, the extensional model, attributes a finite duration to both the acts and the contents of consciousness. Consequently, if, as Husserl had it, "the perception of a temporal object itself

\footnotetext{
${ }^{4}$ Here we have slightly modified Hartle's model by stressing the element of the fading of retained experiences. Callender (2017, ch.11) uses IGUSs to explain our feeling of the passage of time without assuming its reality.

${ }^{5}$ Clearly, the succession of experiences is kept together or integrated by the fact that this nested information is stored by the same subject. See below.
} 
has temporality"6, and if perception of temporality does not consist only in a perception of its duration but also possesses a structural order of succession, according to $\mathrm{M}_{3}$ the relation "earlier than" holding between the temporally extended content of the acts of consciousness is typically the same relation as that holding between the temporally separated acts. That is, events in the world unfold in time and our experience of them generally mirrors this temporal unfolding (Phillips 2014). Despite experimentally accessible distortions in the milliseconds range leading to temporal illusions and to the feeling of a smooth flow of events (Dennett and Kinsbourne 1992, Gruber et al. 2015, Power 2011), in the vast majority of cases the temporal order of the phenomenal contents is reflected in the temporal order of the acts of awareness.

It must be noted that an evaluation of all of these models very soon generates a choice between two different approaches. The three models in fact are either three alternative, rival and as-accurate-as-possible descriptions of the way in which we seem to experience time or they are to be conceived as different and incompatible explanations of this very temporal experience, or why we experience time the way we do. And even though explanations are particular kinds of descriptions, their nature is clearly characterized by an attempt of making us understand something that we take to be a fact. In this section, we will opt for the second option, without forgetting the simple point that in order to explain $\mathrm{x}$, we must know exactly what $\mathrm{x}$ is. If our task were to describe as faithfully as possible the phenomenology of our untutored time consciousness, it would be extremely controversial to hold that we have a privileged access to our temporal experience. ${ }^{7}$ In what follows, therefore, we will briefly assess in turn the explanatory merits of the three models on the assumption that one or the other is the correct phenomenological account of our experience of time. We will show that even the cinematic model, intuitively the most remote from our experience, can offer some explanation of the way time appears to us.

From an explanatory viewpoint, in fact, the retentional and the extentional models seem to exemplify the virtue of explanatory power and faithfulness to our experience of time to a greater

\footnotetext{
${ }^{6}$ While Husserl is typically regarded as retentionalist, in some passages he seems to defend an extensionalist model: "it is evident that the perception of a temporal object itself has temporality, that the perception of duration itself presupposes the duration of perception, that the perception of any temporal form itself has the phenomenological temporality that belongs to its irreducible essence" (Husserl 1928/1991, p.24). As a matter of fact, Husserl's name is often associated with the retentional model. However, in the Husserlian tradition it does not make sense to try to measure the duration of an act of awareness, or of its content. According to Husserl in fact, the structure of retentions, experience and protentions is abstract in the sense of being a condition of possibility for our temporal experience. From this perspective, according to Husserl, the distinction between act and content is not well-posed. By endorsing this remark, we limit our attention to the philosophical or phenomenological discussions of the retentional model that do not faithfully follow Husserl and that engage themselves with the durational aspect of our temporal experience. Thanks to one of the referees for having suggested to make this point. ${ }^{7}$ There is a vast literature on this problem. For skepticism about the transparency of first knowledge access to intentional states, see Gopnik (1995).
} 
degree, because the perception of change seems to require a temporally extended content of our mental acts. In fact, $\mathrm{M}_{1}$ needs to postulate some hidden mechanism (in analogy with the 24 frames per second frequency needed in movies to generate visual continuity) in order to explain why, when we perceive motion, the contents of our temporal experience seem continuously changing even if, strictly speaking, they do not, because they are instantaneous. For instance, the fact that the very brief temporal integration mechanisms realized by our brain at very short scales are nevertheless extended in time may explain both why the resulting content of our perception is instantaneous and why we experience a continuity of motion in spite of this unextendedness in time.

A second, more phenomenological explanation, could be given in terms of the well-known color phi illusion, which has been used by Le Poidevin (2007) and Paul (2010) to claim that we can experience motion between two static spots of different colors that quickly blink in succession without any motion of the spots. An analogous mechanism leading to the waterfall illusion - an experience of motion without an object actually moving - has been considered by Prosser (2016) and Arstila (2017), who discuss these findings within the framework of a dynamic snapshot view.

While for a critical evaluation of these two cases we refer the reader to Callender (2017, pp. 239-240), in our context it is sufficient to stress that the cinematic model must regard all of the contents of our perceiving acts as being of a similar nature, namely as something that is intrinsically static (say, the position of a flying arrow), but "animated" by us in such a way that their motion looks continuous. An explanation of this feature, which is certainly possible, looks rather complicated at the phenomenological level, which seems to point in the opposite direction, and this counts as a prima facie but only apparent difficulty of this model vis à vis the other two.

Agreed, $\mathrm{M}_{2}$ and $\mathrm{M}_{3}$ can explain our experience of change simply by assuming that the contents of our acts are themselves extended in time and that, therefore, must have a duration. In fact, any entity that is temporally unextended, like the contents of the static snapshots of the cinematic model, cannot change by definition, at least under the common conception of change. Such a conception entails the identity across time of whatever changes in the contents of our acts, call it $E$, and the fact that at different moments of time the same $E$ exemplifies two incompatible properties, like occupying in a continuous way different locations against a fixed background. This cannot be the case for the temporally unextended contents typical of $\mathrm{M}_{1}$, since each of them is different from any other one and nothing unextended can change.

The cinematic theorist, however, can rebut this objection in at least two ways. 
First, she can construe change and motion as the occupation of different locations at different times. This explanation is not absurd of course, as it corresponds to the solution given by Russell to the arrow paradox in the so called "at-at theory of motion" (Salmon 1977). So even in the epistemically more solid field of physics and the metaphysics of physics change can be regarded as a relation between a location and a time, in which the arrow is at rest at all instants of time. Given this metaphysical underpinning of change, an explanation of our seamless temporal experience is not logically impossible.

Second, along with Prosser, the cinematic theorist can distinguish between a static cinematic model and a dynamic one (the dynamic snapshot view discussed in Prosser 2016), ${ }^{8}$ the latter corresponding to the thesis that our experiences may have an instantaneous content including a "vector rate of change" (Prosser 2016, 123). In this hypothesis, the dynamic snapshot theorist can claim to be able to experience change without any temporal extendedness (of either act or content). Consequently, $\mathrm{M}_{2}$ and $\mathrm{M}_{3}$ would have no explanatory advantage over $\mathrm{M}_{1}$, since in order to perceive change we would not need a temporally extended content belonging to a "specious present".

Furthermore, even if, from a conceptual point of view, change, modulo the remarks below, could be experienced directly only if the contents of our perception belong to a temporal window of a finite non-instantaneous duration, the question whether this extendedness applies both to the content and the act, or just to the content would still be difficult to evaluate and might be decided only if looked at empirical data coming from neuroscience and psychology.

As a general methodological point and ceteris paribus, we are often told that if we apply Occam's razor to theories having the same empirical consequences but obtained in virtue of incompatible explanatory assumptions, we ought to prefer the simpler explanation, and therefore, prima facie, in our case the second and third model. However, why should we prefer simpler explanations? Lacking a clear analysis of what "simple" means (at least in our context), how should we proceed? Retentionalism, for example, is not so "simple", since it may have to include the notion of "the temporal modes of presentation". An extensionalist like Dainton, in turn, relies on notions such as co-consciousness, the unity of consciousness and an inherent dynamism of the specious present. All of these features are hard to make sense of and, possibly, it is for this reason that Dainton regards them as fundamental and irreducible. ${ }^{9}$ In the end, various reasons can be adduced that suggest a comparison of the phenomenological literature with relevant empirical findings.

\footnotetext{
${ }^{8}$ See also Dorato (2019).

${ }^{9}$ We thank an anonymous referee for these important remarks.
} 
First, even if were true that from a conceptual point of view change, modulo the remarks above, could be experienced directly only if the contents of our perception belonged to a temporal window of a finite non-instantaneous duration, the question whether this extendedness applies both to the content and the act, or just to the content would be difficult to evaluate and might be decided only if looked at empirical data coming from psychology and neurophysiology, something that we will do in the following sections.

Second, we have seen why an appeal to explanatory virtues and faithfulness cannot cut ice, since all models can formulate an explanation as of why we perceive, say, continuous change. We should try to overcome the stalemate by invoking empirical considerations.

Third, if the acts of consciousness necessary for perceiving temporal relations can be distinguished from what is represented by them (their content), it could be argued that the three models are not exhaustive. Then, one may want to consider a fourth possible option, suggested by merely combinatory reasons: we could have temporally extended acts of consciousness whose content is however temporally unextended, a possibility that, as far as we know, in the literature has not been discussed. In Table 1 this fourth model is labeled anti-retentionalist $\left(\mathrm{M}_{4}\right)$.

In a word, we hope that this section has persuaded the reader that the difficulty of choosing among these models only on the basis of their explanatory value suggests a different strategy, based on empirical research. Even if we were to conclude that empirical research cannot solve the dispute between these models, the negative result would still be relevant in order to judge the epistemological status of purely phenomenological discussions, which, at the current level of knowledge, would have to be regarded as wholly underdetermined by empirical data. This by itself should not be interpreted as a criticism of phenomenological approaches, given that the under-determination of scientific theories by data is considered by many philosophers to be an unavoidable feature of our knowledge of the world (even in the empirically most robust empirical science, physics). In another sense, if a comparison with the psychological research that we will present in the remainder of the paper were to prove unhelpful, we could interpret our conclusion as a further evidence in favor of Prosser's (2016) skeptical view that a decision among these three models is impossible, since it presupposes a "Cartesian Theater" account of consciousness that has been famously attacked by Daniel Dennett (1992). According to Dennett, this wrongheaded account regards experiences as inner pictures in front of which the subject sits as if she were watching a show.

\section{Temporal-mechanisms: empirical evidence}

There are many different neurophysiological and psychological conceptualizations 
regarding temporal-processing mechanisms, which make it difficult to juxtapose naively one empirically-based model with the above phenomenological models of temporal experience. ${ }^{10}$ However, different empirical lines of evidence may be summoned that show commonalities, that is, principal mechanisms and effects, which can be related to important conceptual aspects of the phenomenological models under question.

Before briefly presenting a selection of the relevant empirical literature, we deem it appropriate to anticipate our conclusion, which is that the extensional model seems to be better confirmed by findings in the neuroscience. ${ }^{11}$ It pertains to the duration of up to a few seconds, the experienced moment. The cinematic model could instead potentially apply to the very short time range of milliseconds, but to our knowledge so far there is no convincing empirical evidence in its favour. The retentional model might also apply, as it may be more adequate for temporal perception of longer intervals that are not experienced within the present moment but require working memory capacities. To these models we add and make explicit a strong "prospective" component, meaning that the act of consciousness is directional in the sense of being anticipatory.

\subsection{Perception of temporal order and temporal integration}

In order to prepare the ground for comparing the philosophical models with relevant empirical data, we should begin with the elementary perception of temporal succession. In this respect, one has to differentiate between the perception of temporal separated-ness (of nonsimultaneity) and the perception of temporal order (Pöppel 1997, Vatakis et al. 2008). The importance of this distinction for our problem lies in the fact that while in the former case a time asymmetric order of causation cannot play any role (no temporal order is perceived), the latter raises the issue of the possible dependence of the temporal order on the causal order. In experiments assessing thresholds for the perception of non-simultaneity versus simultaneity, temporal resolution depends on the sensory system involved, the lowest threshold of detection being observed in the auditory modality is within 2 to 3 milliseconds (ms) (Lacker and Teuber 1973, Lotze et al. 1999); the tactile and visual system have higher thresholds, in the range of tens of milliseconds (Elliott et al. 2007, Giersch et al. 2013, Kirman 1974, Poggel et al. 2013). The perception of non-simultaneity, however, does not imply the capacity of detecting the temporal order of the two events, that is, which of two events appeared before the other. This

\footnotetext{
${ }^{10}$ For an attempt in this direction, see Gallagher and Zahavi (2008) with their reference to the theory of dynamical systems. For an interesting review of another aspect connecting phenomenology and neuroscience, see Holcombe (2015).

${ }^{11}$ Excepting the anti-retentional model, for which no empirical evidence can be provided.
} 
capacity of temporally ordering auditory, tactile or visual stimuli has higher thresholds (Babkoff and Fostick 2013, Pöppel 1997). Many studies have shown how the perception of temporal order of two short events in different sensory modalities is only possible when the events are separated by temporal intervals of about 20 to $60 \mathrm{~ms}$ (e.g. Exner 1875, Fink et al. 2006, Hirsh and Sherrick 1961, Szymaszek et al. 2009). Below the threshold for detection of non-simultaneity, two events objectively separated by a few milliseconds are nevertheless perceived as happening at the same time, while below the correct temporal-order threshold stimuli might be perceived as non-simultaneous but their true order cannot be reliably detected.

When multisensory information of longer duration is presented, inter-stimulus intervals of up to 100 to $200 \mathrm{~ms}$ may have to occur before an observer is able to distinguish the asynchrony, i.e., the fact that the visual and auditory stimuli were not presented at the same time (van Wassenhove 2009, Vatakis and Spence 2007). Related conceptualizations have focused on temporal integration mechanisms that are bound to neural system states defining a 'perceptual moment' (e.g. Elliott and Giersch 2016, Pöppel 1997, Stroud 1955, White 2018). Whatever underlying mechanism is assumed, it has been difficult to empirically validate underlying models of temporal-order detection and of the constitution of the experienced moment (Madl et al. 2016, Ulrich 1987, Yarrow and Arnold 2016). Nevertheless, the temporal order threshold is the smallest interval at which two events have a clear temporal relation of precedence. The conscious experience of sequence are based on this elementary temporal relation between two events to be judged as " $A$ occurs before $B$ " (Wackermann 2008) ${ }^{12}$. Perceiving the temporal order of events is thereafter fundamental for understanding the causal structure of the world; it has been shown that the ability to detect the temporal order of events (accurateness in temporal-order detection) is a stable trait in humans (Grabot and van Wassenhove 2017). What these authors take for granted is that the temporal order of events grounds the causal order, but more work should be devoted to clarify the possibility that the reverse order of dependence is the case: namely, that the temporal order of events depends on our primitive ability to perceive causal relations between them. From Kant onward, these theories, falling under the label causal theories of time, stress the role of memory in establishing the temporal order of events (see, for instance, Mellor 1998): to the extent that a memory trace is an effect of a previous experience (its cause), causal relations allow us to establish the

12 Recent empirical evidence suggests that visual temporal-order processing may also happen on an unconscious level below the temporal-order threshold; that is, on an implicit behavioral level one can show how temporal-order information is processed albeit not consciously detected (Elliott \& Giersch 2016). Importantly, this unconscious coding of temporal ordering has been discussed as creating the feeling of the continuous passage of time (Herzog et al. 2016). See before our comments about the voluntariness of acts unifying temporal successions. 
temporal order of events and not just when multisensory information is involved. In other words, the relation of temporal succession depends on a primitively conceived causally asymmetric relation. In this perspective, and for all models under discussion we could be aware of an order of temporality only due to intervention of working memory, which would then play a pivotal role in our perception of time: I could not be aware that a sound is before a light signal if I didn't remember the first event while perceiving the second.

In evaluating the above models, let us note that from the neurophysiological perspective, the objective physical time (duration) that is necessary for our brain to produce a single, subjective experience of succession is finite and not infinitesimal, a fact that is obviously noncontroversial. What is controversial, however, is whether this fact is sufficient to rule out the cinematic model in the form of the dynamical snapshot model (according to which "experience has an instantaneous model that includes vector rate of change", Prosser 2016, 123). The color phi or the waterfall illusions are probably based on neuronal mechanisms operating in the millisecond time range (Arstila 2017, Paul 2010, Le Poidevin 2007). It has therefore been argued that for these illusions a dynamic version of a cinematic snapshot model could hold (Arstila 2017, Prosser 2016). We argue that such a mechanism is possible for a special case of experimentally-induced illusions in the very short time range of neurophysiological integration.

To come back to the analysis of temporal-order perception, empirical evidence for these "threshold phenomena" points to discrete processing steps in perception on different temporal scales. Below the temporal order threshold two events are treated as co-temporal. Although they might appear non-simultaneous, their temporal order cannot be reliably indicated. Thus, such a temporal-order threshold defines a 'functional moment' of integration with some tens or hundreds of millisecond duration (Wittmann 2011). Also in sensorimotor processing tasks, a temporal border of around $300 \mathrm{~ms}$ is delineated when subjects are instructed to tap with a finger consecutively on a button. Only with tapping intervals longer than ca. $300 \mathrm{~ms}$ are subjects able to sequentially distinguish and temporally control each individual finger tap (Peters 1989, Wittmann et al. 2001). These and many other studies show how sequentially evolving events are temporally integrated in discrete windows or processing cycles (for overviews, see Elliott and Giersch 2016, Pöppel 1997, van Wassenhove 2009, Wittmann 2011, 2016). Overall, temporal integration of stimuli with sub-second duration happens over several different time scales from a few hundreds to a few tens of milliseconds (White 2018) and depends on the phases of oscillations with different frequency bands (Ronconi et al. 2017). These oscillations have, for example, an active role in parsing the acoustic stream in speech and music in at least two different temporal windows, in segments of around $30 \mathrm{~ms}$ (gamma band) as well as around 
$200 \mathrm{~ms}$ (theta band) (Giraud and Poeppel 2012, Teng et al. 2017). These two timescales of around $30 \mathrm{~ms}$ and $200 \mathrm{~ms}$ are detectable in various experimental outcomes revealing two groups of temporal visual processing mechanisms. These mechanisms have the purpose of extracting perceptual qualities that work in unison to establish a unified visual experience (Holcombe 2009).

It is on the time scale of around $300 \mathrm{~ms}$ that Dainton (2008) identifies the duration of the extensional present: "Tap a table with your fingers, at regular intervals of about a second; after each new tap, ask yourself if you can still hear its immediate predecessors. If the span of your auditory specious present is anything like mine, the answer will be 'no'." (Dainton 2008, 367). Dainton's example of the extended present thereafter relates to a temporally unified whole defined by the experienced fusion of perceived elements, in his example a sequence of auditory events produced by finger taps on a table. Following from the functional analysis of sensory thresholds, this specious present is a functional moment of event integration spanning duration of around $300 \mathrm{~ms}$. Dainton's view stems from the intuition that for two events to be experienced within the same extended present they should have the same "phenomenal force". The sensory impression of an event happening a second ago is less strong and therefore outside the window of the perceptual now. We concur with this view, as it is indicative of an extended perceptual moment that we label "the functional moment" in the range of milliseconds or less than a second. This is striking evidence that, at this time scale, Dainton's extensional model as he presents it from a purely phenomenological viewpoint, is confirmed. According to Dainton, this functional moment of integration identified to last some hundreds of milliseconds would define the extended present moment.

\subsection{The timing of acts and contents of consciousness}

Dainton's claim that the act is extended as in the extensional model can be confirmed also by psychological experiments related to the attentional blink effect in visual perception. If subjects have to search for two target letters presented sequentially in between distractor letters, target letter no. 2 can only be detected after an interval of 200 to $400 \mathrm{~ms}$ following the appearance of target letter no. 1 (Marois and Ivanoff 2005, Ward et al. 1996). The act of awareness towards a second content in this specific case is possible only after a certain period of time has gone by, i.e. a process for detecting event 2 can be instantiated only when the first underlying process responsible for detecting event 1 has ceased. It should be clear why this finding is important for our distinction between act and content. The discreteness of the brain's processing mechanism lasting some tens or some hundreds of milliseconds can be seen as 
indicative of a certain duration of the act of awareness. The attentional system would open up for a new input in an oscillatory way with a periodicity lasting duration $d$, i.e. from 200 to 400 ms. After a period $d$ a new window opens up for detecting a following stimulus, forming the building blocks or correlates of an extended act of awareness.

Cinematic theorists, however, could object to the claim that acts of consciousness have duration. First, they could maintain that the inter-stimulus interval $d$ ranging from 200 to 400 ms, necessary for detecting target letter no. 2, does not reflect an extended act of consciousness lasting for $d$. A near instantaneous act $\mathrm{A}_{1}$ could open up for target no. $1\left(\mathrm{E}_{1}, \mathrm{P}_{1}\right)$ and only after $d$ has elapsed an act $\mathrm{A}_{2}$ opens near instantaneously for target no. $2\left(\mathrm{E}_{2}, \mathrm{P}_{2}\right)$.

However, there are various objections to this criticism.

1. This seemingly plausible mechanism accounting for an unextended conscious act would only function in a physical world with fixed periodicities in the millisecondsto-seconds range, when an act opens up for anticipated, regularly appearing, physical events such as in laboratory tasks designed by experimental psychologists, who program a stimulus to appear exactly every $300 \mathrm{~ms}$. In a real-world scenario instead, temporally extended acts of consciousness (actually the neural correlates of such acts) are necessary in order not to miss events that do not occur exactly regularly but with a jitter. Alternatively, one could imagine a series of unextended conscious acts through which incoming new information is gathered at a high frequency. That would be the equivalent to a film camera which operates with one single, stable frequency. Then, however, one would have to assume an additional mechanism for explaining why only after a certain number of such acts, after around $300 \mathrm{~ms}$, the second target can be identified. It has to be emphasized that whereas the above-mentioned researchers point to the specificity of certain time ranges for cognitive functions, we claim that temporal integration has to be more flexibly adjusted according to different processing demands. That is, regular, temporally rigid, time frames would be not flexible enough for capturing the statistical properties of the world (White, 2018). A conceptual compromise between these two viewpoints (the rigid and the flexible) would consist in accepting the empirically found time-frames in the millisecond range referred to above but allowing for a greater temporal flexibility of these biological mechanisms working in an approximate time range.

2. Furthermore, the cinematic theorist could argue that in a strictly-controlled sensorimotor system such as that of internally generated eye movements, the notion 
of a fixed temporal sequence of near instantaneous acts would seem more plausible. The system "knows" when and where it should look. But even as far this second criticism is concerned, eye fixations have certain duration of fractions of a second. Metaphorically speaking, this system functions not unlike a windscreen wiper which shortly clears the windscreen and then rests for a certain period of time (the eye fixation period) before clearing the window again (the saccade). Antagonistic processing models of magnocellular ( $\mathrm{M}$ system) and parvocellular (P system) pathways underlying the control of eye fixations and saccades comes close to this metaphor, where the fast $\mathrm{P}$ system would interrupt the processing of the slower $\mathrm{M}$ system and thereby would enable the intake of novel visual information for a certain duration (Breitmayer 1980). Empirical data show how comparably stable durations of eye fixations for information intake, alternating with saccades (quick eye movements), are found depending on underlying preattentive (150 to $250 \mathrm{~ms}$ ) and attentive (around $500 \mathrm{~ms}$ ) processing mechanisms (Velichkovsky et al. 2002).

Furthermore, as an additional evidence in favor of the extensional model, the general rhythmic nature of local and global neural activity with multiple frequencies, as recorded with the electro-or magneto-encephalogram (Buzsáki 2006), is supportive of oscillatory neural models underlying discrete information processing in the brain (van Wassenhove 2009, 2017), a capacity that can be more plausibly interpreted in the context of extended acts of awareness. For example, visual sensory input is most accurately detected when a stimulus appears at a certain phase of recorded oscillations with a period of 7 to $10 \mathrm{~Hz}$ (Busch and VanRullen 2010, 2014). This means that the detection ability decreases from a maximally sensitive phase in a given oscillatory cycle, before following a trough it increases again to complete the period. This ability does not work in an absolute "on" (for a near-instantaneous moment) and "off"-mode, but the detection probability is described mathematically as oscillatory. It could be argued that this oscillatory processing in the 7-Hz range as assessed with EEG is related to the likelihood of a stimulus to be consciously perceived (Busch and van Rullen 2014).

Not only are the acts of conscious awareness extended, as a consequence of their being bound to oscillatory neural mechanisms, but also the conscious contents of these acts are extended. This is due to the persistence of objects in the field of perception as static or moving. The macroscopic world, including its embodied perceiver, is made predominantly by more or less solid objects which change their properties not observably or too slowly (Butterfield 1984). Within our present experience we may sense the slowly moving clouds above the static 
mountain scenery in front of a (static) blue sky. As smooth as the movement of the clouds may appear in the otherwise static scenery, the underlying oscillatory neural machinery processes the sensory information in discrete ways (van Rullen and Koch 2003, Wittmann 2016).

Even shortly lasting objects in the field of perception in the range of tens of milliseconds can persist much longer as representational entities than their physical counterparts. For example, the now classic Sperling experiments concerning the concept of sensory storage have revealed how sensory information is stored for a duration that lasts longer than the actual stimulus duration (Sperling 1960). When subjects are presented with an overload of acoustic or visual stimuli (typically one on several lines of letters or acoustic information from one of several sound sources), only those items can be memorized to which attention is directed. When a cue is presented shortly after stimulus exposure, indicating which stimuli have to be reported, subjects report the presented information from that line or the sound source. This sensory storage function is termed iconic (visual modality) and echoic (auditory modality) memory (Darwin et al. 1972, Sperling 1960). Letters or syllables with an experimentally controlled exposure time of only $50 \mathrm{~ms}$ are present in this sensory storage for up to several hundred milliseconds - depending upon physical characteristics - before information is lost, if attention is not directed to the specific location. That is, short events in the milliseconds range presented in the visual or acoustic field do not decay immediately after offset of appearance but are still represented for a short while, although they - physically speaking - have vanished. ${ }^{13}$ Notice that this phenomenon is not just to be interpreted as a lag or a delay of our becoming aware of a stimulus that just occurred, but it is rather about the duration of contents of sensory stimulation that become conscious if attention is directed towards the information they convey. To sum up these thoughts, the contents of consciousness are extended as persisting static or dynamic elements in our perceptual field and very short-lived stimuli persist longer than the physical stimuli on a pre-conscious representational level.

\subsection{Temporal windows of presence}

Besides the above-presented lower-level limiting factor of temporal resolution, the

13 These data have interesting consequences also from the point of view of the thorny problem of the relation between bodily states and mental states, which here must be left aside. For instance, an identity theory between mental and brain events seem to favor the extensional models. In fact, the unmatched temporal properties of the neural/physical events and the mental events (the former temporally extended, the latter unextended) may seem to render rather implausible the models $\mathrm{M}_{1} \mathrm{M}_{2}$ and $\mathrm{M}_{4}$. If the brain events involved in the perception of succession are temporally extended, the mental events to which these brain events are token or type identical are temporally extended as well. Since the cinematic and the retentional model assume that the mental act is durationless while the content is not and the reverse hold for $\mathrm{M}_{4}$, an identity theorist should favor the other two models. 
temporal-order threshold, which defines the interval below which two events are treated as cotemporal, and above which the elementary temporal relation between two events is perceived, is there also an upper limit of temporal experience? The perception of clock-hand movements of a mechanical clock, a thought experiment introduced by C.D. Broad, reveals an upper limit of temporal perception (Hoerl 2009, 2013, Kiverstein 2010, Wittmann 2016). We are able to see the second hand of the clock move, but we do not see the movement of the hour hand. Even if the movement of the hour hand is mechanically constructed such that it moves continuously, its movement cannot be perceived because it is too slow for us (our perceptual system). This fact indicates that there exists an upper limit of temporal experience.

The two limiting temporal factors of perception lead to the suggestion of a window of presence within which we are able to detect change. The two aspects of consciousness of (1) perception of change and (2) the awareness of a present moment are thus intertwined (Metzinger 2004). We can only detect change (i.e. the movement of the second hand) when perceptual experiences cover a sufficiently extended interval of time in which these changing events happen. Accordingly, as William James (1890) had already realized more than a century ago without relying on precise experimental measurements, present experience is not a durationless instant in time but is embedded in a temporal field that is stretched in time. Succession, rhythmic grouping and motion can constitute our experience only in virtue of the extended temporal window of presence (Stern 1897). Husserl (1928/1991), Kiverstein (2010), and Lloyd (2012) also agree that the content of our experience is stretched in time. Within this extended present moment our experience exemplifies a complex temporal structure, the parts of which are temporally ordered (Kiverstein and Arstila 2013), such as when one hears the ticktock of a clock or when one rhythmically groups musical beats into auditory temporal gestalts of 1-2-3, 1-2-3, etc. (Szelag et al. 1996, Linares et al. 2019).

In case of the hour hand, the subjective present is temporally not extended enough for the slow changes to be experienced. Hoerl (2009) thus summarizes that "temporal experience has an upper and a lower limit, in the sense that only temporal phenomena that are discriminable within these limits (i.e., that don't happen too fast or too slow) can be perceived. These limits [...] reflect empirical, and empirically demonstrable, limitations of our perceptual systems, and are to be explained on the level of information-processing psychology." (Hoerl 2009, 11) Experience of change thereafter is defined by the upper and lower boundaries of temporal perception: what is being experienced as change unfolds in the extended present. The question 
then arises: does it make sense to ask how long is the present moment? ${ }^{14}$ Can a temporally extended interval of present-ness be experienced via a momentary act? An answer to these questions will prove relevant to our aim of evaluating the different phenomenological models on an empirical basis.

By relying on earlier conceptual and empirical work (e.g. Fraisse 1984, Montemayor 2013, Montemayor and Wittmann 2014, Pöppel 1997, Varela 1999) one can argue for at least two levels of extended present, one in the range of a few seconds, the experienced moment, which is related to temporal segmentation in perception and action, and the other in the range of multiple seconds, mental presence, which generates the continuity of experience through working-memory processes.

The experienced moment is a perceptual whole of immediate sensory experience of what is perceived 'now': the movement of the second hand on the clock face, the musical phrase emanating from the radio, the warm feeling of the hot water as I sink into the bath tub. This experienced moment fits the extentionalist model, where we experience change happening in a certain order of succession that mirrors the unfolding of physical events in the world and therefore their order of succession. The "naïve view", where there is a correspondence between the unfolding of experienced events and the unfolding of events in the world (Phillips 2014), therefore, is accurate within the temporal limits of the experienced moment. Some experimental studies show how an integration window of 2 to 3 seconds duration underlies the perception of complex, naturalistic visual sequences (Fairhall et al. 2014). Moreover, anticipatory timing of movement in this time range functions most accurately and effortless within a window of a few seconds (Mates et al. 1994, McAuley et al. 2006; for an overview, see Dorato and Wittmann 2015, Pöppel 1997). By measuring event-related potentials of the brain employing a specific experimental paradigm (assessing mismatch negativity), it has been shown that deviations from the physical characteristics of repeated stimuli lead to higher amplitudes with inter-stimulus intervals below $3 \mathrm{~s}$ than with longer intervals (Wang et al. 2015, 2016). This has been interpreted as indication that the brain is most sensitive to processing temporal intervals up to $3 \mathrm{~s}$.

In our opinion, many researchers and philosophers have relied too heavily on passive perceptual processes and did not consider the sensorimotor basis of human activity which is essential for understanding consciousness. Humans most effortlessly anticipate and integrate

\footnotetext{
${ }^{14}$ Edmund Husserl (1928/1991, p. 32) mentions that the temporal field must have a certain quantifiable duration: "which is manifestly limited, precisely as in perception's case. Indeed, on the whole, one might dare to assert that the temporal field always has the same extensions."
} 
sensory events through motor behavior with intervals not expanding three seconds (Mates et al. 1994, McAuley et al. 2006). Within this context the philosopher Andrea Roselli (2019) favors the extended temporal model as he defines the present as the time interval in which an individual can react without having the feeling of being too late. This is in essence the impression of being in synchrony with the world within an extended frame of sensorimotor activity. For him, if we can react with two temporally separate movements to two different events, these two distinct events are temporally separated and not within one present moment. Two events which I might be able to perceptually separate but which I cannot act upon separately, because the time interval between is too short, can be treated as co-conscious, as falling within one present moment.

It is a matter of conceptual debate about empirical findings to decide whether the experienced moment or the feeling of 'nowness' stems from one temporal processing mechanism with a defined duration of around 2 to 3 seconds (Pöppel 1997) or whether several independent mechanisms with variable duration - but nevertheless in a similar range - can be identified (Kent 2019, White 2017). Brain imaging work points to several neural integration levels, measured as how long recent events influence moment-to-moment neural activity, visual and auditory narrative elements being used as stimuli, i.e. movie and sound clips (Hasson et al. 2008, Lerner et al. 2011). The integration levels range from the sub-second to several-second range and form a hierarchy of progressively longer temporal processing windows within working-memory function. Moreover, these processing windows to some extent adapt to the rate at which information is arriving by means of temporal rescaling - within limits being variable in duration (Hasson et al. 2015). The processing windows do not have a fixed duration, but they stem from the contingencies during the integration of dispersed cell assemblies in an approximate time range (as discussed by Gallagher 2017a). However, not all of these temporal integration levels necessarily pertain to the experienced moment of conscious awareness about what is happening right now. Temporal integration mechanisms of the brain on several longer time scales have functional properties for the organism but they are not necessarily associated with the rather short experienced present (Lockwood 2005). The experienced moment refers to what is experienced as co-present in a window of 'nowness'. This temporal window will be quite short, probably not more than 2 to 3 seconds, but maybe, as others have proposed even shorter (Kent 2019, Lockwood 2005). We propose that this form of temporal experience can be related to the extensional model where the acts and contents of consciousness are extended. If we take up the definition of "what is experienced as co-present in a window of experienced "nowness"", accordingly, the time interval to which the extensional model $\mathrm{M}_{3}$ applies must be 
rather short. Dan Lloyd (2004, 2012) illustrates this extensional property of present experience with the Beatles song "Hey Jude". As soon as Paul McCartney's voice intones the "Hey" we all expect the "Jude" to come, even though the word has not yet been voiced, and it is (physically) not present. It is already mentally present as actualized through long-term memory traces. Similarly, when we hear the "Jude", the "Hey" is still resonating with us even though, physically speaking, the air vibrations are no longer existent. That is, we experience a temporal unit of "Hey Jude" with an emphasis first on the "Hey" and then later on the "Jude". These two experiences $E_{1}$ and $E_{2}$ are representationally speaking co-present. Thus, in this example we have the two extended events (contents of consciousness) "Hey" and "Jude" $\left(\mathrm{E}_{1}, \mathrm{E}_{2}\right)$ as forming an experienced unit integrated by an act of consciousness..$^{15}$

In contrast, longer temporal integration mechanisms relate to the time range of the working memory capturing short-term memory traces related to mental presence (Wittmann 2011). Mental presence is a longer interval of integration for enabling the continuity of experience through working memory in the range of multiple seconds, thereby allowing the maintenance of cognitive operations and emotional feelings. The neuroscientist Goldman-Rakic (1997) notably described working memory as providing "a temporal bridge between events - both those that are internally generated and environmentally presented - thereby conferring a sense of unity and continuity to conscious experience". That is why, after a short interruption, we can again follow up on a task we were just doing. However, the past visual experience of watching a movie is not co-present anymore as visual experience, when after the interruption of 10 seconds I again follow the movie. This relates to persistent neural activity, generated during a short-term delay period by reverberating discharges in neural networks including the prefrontal cortex; this is the mechanism that keeps information over the course of multiple seconds in working memory (Constantinidis and Klingberg 2016). This form of temporal processing can be related to the retentional model with extended contents of consciousness. These contents show up as short-term memory traces and are not dependent on an extended mechanistic act of consciousness but to the slow fading out of memory (i.e. the process of forgetting). In the retentionalist's account experience is intentionally directed to the past, present, or future and a just passed event is available through working memory-type components (retentions) that are actualized next to momentary sensory experience in an extended perceptual presence. However, we see one main obstacle for accepting the retentional model, which assumes that the acts of

\footnotetext{
${ }^{15}$ We are aware the Dan Lloyd uses this example in favour of the retentional model. In our opinion, shorter intervals are covered by the extensional model; longer intervals by the retentional model. The question would be whether "Hey Jude" would fit into a window of presence according to the extensional model. That is the debate.
} 
consciousness are unextended. Any biological process takes time. Since we are dealing with brain processes which underlie acts of consciousness, we have to state that an unextended act of consciousness is biologically not plausible. The mechanistic basis of any act of consciousness necessitates an interval of time and thus is extended (Longo \& Montévil 2011). As argued above, these considerations also apply to the cinematic model, given that both models share the hypothesis that the act of consciousness is unextended. Consequently, the arguments presented above against the claim that within the cinematic model the act is unextended also apply to the retentional model.

There could nevertheless be a feasible way to circumvent the problem of making sense of the unextended acts of consciousness postulated by the retentional model as it is usually understood. One could assume passive memory processes within working memory, where just experienced events recede into the past without the presence of acts of consciousness. In such a conceptualization, longer time intervals in the content of our experience would be involved without an explicit mechanism for a series of unextended acts of consciousness. However, this move would change drastically the assumptions of the retentional model as presented above.

Two recent conceptualizations by Northoff $(2014,2016)$ and by Lloyd $(2004,2012)$ link specific neural activation to James' (1890) and Husserl's (1928/1991) idea of “inner time consciousness". In these two approaches, the question of whether act and content of consciousness are extended is not explicitly addressed, but a discussion of this question should be conducted by relating the phenomenological view of an extended present with specific neural processes. Northoff $(2014,2016)$ identifies slow cortical potentials with something that can potentially enable the temporal width of experience (as extended present moment) through the temporal integration of discrete time points. Due to their long phase duration as low-frequency fluctuations, such slow cortical potentials would integrate different stimuli and their associated neural activity from different brain regions (Schmidt et al. 2016). Such temporal integration across regions of the brain would enable consciousness over time, the feeling of extended 'nowness'. Lloyd $(2004,2012)$ with his empirical work employing fMRI technology identifies the default mode network (comprising midline structures of the brain) with temporally fluctuating activity, processes that might encode the flow of events over time as experienced temporality.

\section{Why do the temporal models need the addition of a predictive component?}

Our knowledge about the anticipatory and enactive character of perception and experience (Gallagher 2017b, Noë 2004, Varela et al., 1991/2016) presupposes the existence 
of various inference problems that our brain constantly solves (Friston and Kiebel, 2009, Wacongne et al. 2011). In the context of the "predictive coding" concept (Friston 2010; for a precursor model see von Holst and Mittelstaedt 1950), the brain is constantly predicting what might happen based on prior experience and correct the expectation through a specific feedback mechanism (Eagleman 2011). In normal waking consciousness we are constantly making shortterm predictions in order to minimize surprise, which is defined as the difference between prediction and actual outcome. Surprise means that the organism has to adapt its behavior, a fact that in turn increases energy consumption. This is what an organism wants to avoid; therefore, the goal is to reduce prediction error for saving energy expenditure. If temporal structures recur in the environment, adequate prediction means the proactive attentional and motor preparation for upcoming events (Nobre and van Ede 2018). Social communication is about predicting and explaining the behaviors of other people as embodied interaction (Fuchs and de Jaegher 2009). Dynamical inter-bodily, verbal and non-verbal, interactions give rise to measurable synchrony patterns among individuals (Froese and Fuchs 2012, Tschacher et al. 2012). Given the indubitably anticipatory character of our experience and its evolutionary evidence, it seems quite plausible to argue that the extensional and even retentional models endorsed in the sense given in the previous section ought to be supplemented with a predictive component.

As an illustration, think of well-known, everyday life examples involving the motor schemas that enable us to catch a ball. In these cases, we automatically calculate the time of arrival and anticipate our catching the ball by moving our arm beforehand (Bar 2007). Our experience of the present "includes" the future event in such a way that the retained events, the primary impression and the anticipated event cannot be sharply separated, and differ only by the vivacity with which they are presented to us: this happens when we listen to music and anticipate a note, or when we suggest a word to someone who is speaking to us and does not know how to go on or finish the sentence.

Whereas predictive coding and sensorimotor anticipation are related to the millisecond and second range, anticipatory components also play a role in longer temporal intervals, where evolutionary arguments may suggest the possibility that some brain structures piggybacked on the former much simpler mechanisms. We should consider the kind of information that is retrieved from our biographical and narrative self to be essentially goal-directed and therefore future-oriented as well. This seems to be required by the fact that many of our decisions, especially those that are not routine-like such as taking the subway or the car to go to work, need to be considered from the viewpoint of our "future self", namely by anticipating now how 
we would perceive ourselves in the future (Szpunar et al. 2014).

This is not to be understood just in terms of the fact that these decisions require a sort of temporal neutrality vis à vis the present moment (see Brink 2013) and therefore considerate attention to working memory, more or less remote past and anticipated future. In addition, when our decisions are morally relevant, they also involve our consulting, filtering out and retrieving appropriate bits of our autobiographical self in order to find out the "kind of person we were and wanted to be in the past" (our past commitments) and therefore also the kind of person we want to become in the future. Affective asymmetries between anticipated future and past pains are complemented by other asymmetries: knowledge asymmetry means that we know less about the future than about the past; the future is open to our action while the past is settled and unchangeable; a causal asymmetry means that only the future is potentially controllable. These and other temporal biases explain why according to Callender (2017) we care more about the future than the past.

It is interesting to note that a reference to extended episodic contents of time consciousness is also of paramount importance to explain our capacity to anticipate, experience, and remember an objective succession of physical events. This capacity enables us to look at the same event (say, our next birthday) from three different temporal perspectives even when they are separated by, say, months (the same event being anticipated, experienced, and then remembered). These projections of the self in time make possible our planning the future course of action and therefore rational decisions.

However, what are the grounds for this capacity? During the experienced moment we integrate an objective succession of physical events by predicting, experiencing, and retaining events in a small interval of time spanning a few seconds. This capacity is shared by highly developed mammals (Gerster and Fazio 1995). However, it is the mental presence that is responsible for our full-fledged feeling of the flow of time across the time span of working memory, and within which long-term memories and long-term future expectations are actualized. As Augustine had already claimed, we measure the length of non-existent, future time by encompassing the future experience in the present experience via a distensio animi (a "stretching of our mind"), and then imagining how that future event will be like when it will become past: all of this relying on our inductive capacities.

The role of induction in explaining the passage of time as an extension of the experienced present (a few seconds) and the mental present (several seconds of working memory span) is evident from the fact that future outcomes of our actions, when they fall outside the temporal scope of this twofold present, are "imagined" but not "perceived directly". However, we must 
not forget that the identity conditions for the continuity of a self in time necessarily involve future projections, based on anticipated conditions that are influenced by our past experiences. These projections into the future (a sort of mental time travel) are based upon long-term autobiographical as well as episodic memories, and their function is to form expectations of what might happen. Clearly this function contributes to survival and according to some it is even at the origin of language (Suddendorf and Corballis 2007, Yi et al. 2009). Even more radically, we could say that the particular information that we retrieve within the boundless amount of data concerning our autobiographical self depends in part on our present goals and therefore on what we want to achieve. Correspondingly, we interpret and filter out our past experiences in terms of what is occurring in the present and therefore of what we want to achieve in the future.

In a word, it is only because (1) we first anticipate our future, say, sitting in the dentist room, an event occurring in 10 days from now, (2) we then experience the root canal treatment as it momentarily occurs, and finally (3) we remember the very same event a day later as past experience that we are capable of looking at the same event (the dentist session) from three different temporal mental perspectives. But this capacity is exactly what is necessary and sufficient for creatures like us to believe in the reality of our experience of the passage of time, a capacity that is already present in shorter time intervals, in the experienced present and in anticipations of sensory-motor mechanism. In fact, within the time constraints of experienced presence we directly experience the passage of time as directly felt on the scale of seconds, as the dentist's drill comes closer to our mouth and then drills a hole and then again extracts his tool again. Also on this time scales of several seconds, a future event (the anxiously awaited drill while already sitting on the dentist's chair) becomes present experience (now the drill enters my tooth) and later memory of what just happened (when the dentist retracts the drill out of my mouth). Whether this phenomenology is sufficient to attribute to the metaphysical world a mind-independent passage or temporal becoming is another question that here cannot be treated (see Prosser 2016 for a well-argued negative answer and Dorato 2019 for a critical review).

\section{Conclusion}

Here we argued specifically for the extensional model of time consciousness which, moreover, must contain a predictive component. Neuropsychological findings are indicative of cyclic brain processes which could underlie the discreteness of perceptual processing found in many experimental tasks. We tried to show that the acts of consciousness, - which themselves 
have a predictive, future-directed component - as well as the contents of consciousness, as related to the time range of seconds, are extended as the extensional model has it. However, the dynamical snapshot model and the retentional model have not been definitely ruled out and may apply to phenomena in the millisecond and the multiple-second time range, respectively. Our major criticism concerning these two models is that they assume that acts of consciousness are unextended, which is biologically and neurophysiologically implausible.

In this article, three issues were not discussed in detail. For one, we only scratched the issue of embodiment of perceptual experience pertaining to the conscious self and time. According to the embodied/enactive conceptualization, the first-person perspective is created by the continuous visceral and proprioceptive input from the body, the physical self thereby functioning as (bodily) anchor of subjective experience (Craig 2015, Metzinger 2008). Relatedly, subjective time emerges through the existence of the self across time as an enduring and embodied entity (Fuchs 2017, Zahavi 2005). Second, we did not elaborate on the question whether the passage of time is an ontological feature of the world (see the comment above mentioning Prosser). Thirdly, and relatedly, we did not touch upon the problem of what in experience accounts for the feeling of the flow of time. There is no single experience that we could call 'passage of time' or 'flow' (Callender 2017, p. 228f). Different experiences in the range of milliseconds and seconds, such as movement or change, most likely generate our belief in the passage of time. Moreover, on a larger time scale of expectation and autobiographical memory we experience the "passage of an event" through time (see our example above of visiting the dentist 10 days from now).

Experienced temporality thus is dependent upon different time scales. The extensional model pertains to a short interval of present sensory experience which binds elements into a temporal, co-present and experienced whole. Experienced change and perceived movement extend up to a few seconds. Beyond this short time range of an experienced moment, working memory processes bind together events that are not immediately present in sensory experience.

To sum up, in discussing the three models of temporal consciousness, the cinematic, the retentional, and the extensional model, we presented the distinction between acts of consciousness and contents of consciousness. In reviewing a selection of empirical findings from the cognitive neurosciences we showed how these models can be juxtaposed to different phenomena and mechanisms on different time scales. We favored an extensional model of time consciousness for the experienced present, i.e. a short time range of maximally very few seconds, where the acts and contents of consciousness are both extended. In addition, we show that the retentional model might apply to longer time ranges but the fact that this model 
supposes unextended acts of consciousness makes it less plausible from a biological point of view. Moreover, we added a predictive component as decisive for the understanding of subjective time. 


\section{References}

Arstila, V. (2017). Temporal experiences without the specious present. Australian Journal of Philosophy. https://doi.org/10.1080/00048402.2017.1337211

Babkoff, H., \& Fostick, L. (2013). The role of tone duration in dichotic temporal order judgment. Attention, Perception \& Psychophysics, 75(4), 654-660.

Bar, M. (2007). The proactive brain: using analogies and associations to generate predictions. Trends in Cognitive Sciences, 11(7), 280-289.

BonJour, L. (2002). Epistemology: Classic Problems and Contemporary Responses, Oxford, Rowan and Littlefield Publishers and Inc.

Breitmeyer, B. G. (1980). Unmasking visual masking: A look at the "why" behind the veil of the "how." Psychological Review, 87(1), 52-69.

Brink, D. (2011). Prospects for temporal neutrality. In C. Callender (Ed.), The Oxford Handbook of Philosophy of Time (pp. 383-419). Oxford: Oxford University Press.

Busch, N. A., \& VanRullen, R. (2010). Spontaneous EEG oscillations reveal periodic sampling of visual attention. Proceedings of the National Academy of Sciences, 107(37), 1604816053.

Busch, N., \& VanRullen, R. (2014). Is visual perception like a continuous flow or a series of snapshots? In V. Arstila \& D. Lloyd (Eds.), Subjective Time: The Philosophy, Psychology, and Neuroscience of Temporality (pp. 161-178). Cambridge, MA: MIT Press.

Butterfield, J. (1984). Seeing the present. Mind, 93(370), 161-176.

Buzsáki, G. (2006). Rhythms of the brain. Oxford: Oxford University Press.

Callender, C. (2017). What makes time special? Oxford: Oxford University Press.

Chuard, P. (2011). Temporal experience and their parts. Philosophical Imprint, 11(11), 1-28

Constantinidis, C., \& Klingberg, T. (2016). The neuroscience of working memory capacity and training. Nature Reviews Neuroscience, 17(7), 438-449.

Craig, A. D. (2015). How do you feel? An interoceptive moment with your neurobiological self. Princeton: Princeton University Press.

Crane, T., \& Farkas, K. (Eds.) (2004). Metaphysics: A guide and anthology. Oxford: Oxford University Press.

Crick, F., \& Koch, C. (2003). A framework for consciousness. Nature Neuroscience, 6(2), 119126.

Dainton, B. (2008). Sensing change, Philosophical Issues, 18, 362-384

Dainton, B. (2010). Time and space. New York: McGill Queen's University Press (2 ${ }^{\text {nd }}$ ed.).

Dainton, B. (2011). Temporal experience. In C. Callender (ed.), The Oxford Handbook of 
Philosophy of Time (pp. 420-438). Oxford: Oxford University Press.

Dainton, B. (2012). The phenomenal self. Oxford: Oxford University Press.

Dainton, B. (2014). Temporal consciousness. In E. N. Zalta (Ed.), The Stanford Encyclopedia of Philosophy (Spring 2014 Edition),

$\mathrm{URL}=<$ http://plato.stanford.edu/archives/spr2014/entries/consciousness-temporal/>.

Darwin, C. J., Turvey M. T., \& Crowder, R. G. (1972). An auditory analogue of the Sperling partial report procedure: Evidence for brief auditory storage. Cognitive Psychology, 3(2), $255-267$.

Dennett, D., \& Kinsbourne, M. (1992). Time and the observer: the where and when of consciousness in the brain. Behavioral and Brain Sciences, 15(2), 183-201.

Dorato, M., \& Wittmann, M. (2015). The now and the passage of time. From Physics to Psychology. Kronoscope, 15(2), 191-213.

Dorato, M. (2019) Review of Simon Prosser's Experience Time, to appear in: Philosophy of Science, 4, pp. https://doi.org/10.1086/704971

Eagleman, D (2011). Incognito. The secret life of the brain. Random House, New York.

Elliott, M. A., Shi, Z., \& Sürer, F. (2007). The effects of subthreshold synchrony on the perception of simultaneity. Psychological Research, 71(6), 687-693.

Elliott, M. A., \& Giersch, A. (2016). What happens in a moment. Frontiers in Psychology $6(1905)$.

Exner, S. (1875). Experimentelle Untersuchung der einfachsten psychischen Processe. III. Abhandlung. Pflügers Archiv Physiologie, 11(1), 403-432.

Fairhall, S. L., Albi, A., \& Melcher, D. (2014). Temporal integration windows for naturalistic visual sequences. PloS One 9(7), e102248.

Fink, M., Ulbrich, P., Churan, J., \& Wittmann, M. (2006). Stimulus-dependent processing of temporal order. Behavioural Processes, 71(2-3), 344-352.

Fraisse, P. (1984). Perception and estimation of time. Annual Review of Psychology, 35(1), 137.

Friston, K., \& Kiebel, S. (2009). Predictive coding under the free-energy principle. Philosophical Transactions of the Royal Society B: Biological Sciences, 364(1521), $1211-1221$.

Friston, K. (2010). The free-energy principle: a unified brain theory? Nature Reviews Neuroscience, 11(2), 127-138.

Froese, T., \& Fuchs, T. (2012). The extended body: a case study in the neurophenomenology of social interaction. Phenomenology and the Cognitive Sciences, 11(2), 205-235. 
Fuchs, T., \& De Jaegher, H. (2009). Enactive intersubjectivity: Participatory sense-making and mutual incorporation. Phenomenology and the Cognitive Sciences, 8(4), 465-486.

Fuchs, T. (2017). Self across time: the diachronic unity of bodily existence. Phenomenology and the Cognitive Sciences, 16(2), 291-315.

Gallagher, S., \& Zahavi, D. (2008). The phenomenological mind. Abingdon, New York: Routledge.

Gallagher, S. (2017a). The past, present and future of time-consciousness: From Husserl to Varela and beyond. Constructionist Foundations, 13(1), 91-97.

Gallagher, S. (2017b). Enactivist interventions. Oxford: Oxford University Press.

Gerstner, G. E., \& Fazio, V. A. (1995). Evidence of a universal perceptual unit in mammals. Ethology, 101(2), 89-100.

Giraud, A. L., \& Poeppel, D. (2012). Cortical oscillations and speech processing: emerging computational principles and operations. Nature Neuroscience, 15(4), 511-517.

Giersch, A., Lalanne, L., van Assche, M., \& Elliott, M. A. (2013). On disturbed time continuity in schizophrenia: an elementary impairment in visual perception? Frontiers in Psychology 4(281).

Goldman-Rakic, P. (1997). Space and time in the mental universe. Nature, 386(6625), 559-560.

Gopnik, A. (1995). How we know our minds: the illusion of first-person knowledge of intentionality. Behavioral and Brain Sciences, 18(2), 390-390.

Grabot, L., \& van Wassenhove, V. (2017). Time order as psychological bias. Psychological Science, 28(5), 670-678.

Gruber, R. P., Bach, M., \& Block, R. A. (2015). Perceiving two levels of the flow of time. Journal of Consciousness Studies, 22(5-6), 7-22.

Grush, R. (2007). Time \& experience. In T. Müller (Ed.), Philosophie der Zeit. Neue analytische Ansätze (pp. 27-44). Frankfurt: Klostermann.

Hartle, J. B. (2005). The physics of now. American Journal of Physics, 73(2), 101-109

Hasson, U., Yang, E., Vallines, I., Heeger, D. J., \& Rubin, N. (2008). A hierarchy of temporal receptive windows in human cortex. Journal of Neuroscience, 28(10), 2539-2550.

Hasson, U., Chen, J., \& Honey, C. J. (2015). Hierarchical process memory: memory as an integral component of information processing. Trends in Cognitive Sciences, 19(6), 304313.

Hawley, K. (2015). Temporal parts. In E. N. Zalta (Ed.), The Stanford Encyclopedia of Philosophy (Winter 2015 Edition), $\mathrm{URL}=<$ https://plato.stanford.edu/archives/win2015/entries/temporal-parts/>. 
Herzog, M. H., Kammer, T., \& Scharnowski, F. (2016). Time slices: what is the duration of a percept. PLOS Biology 14(4).

Hirsh, I., \& Sherrick, C. (1961). Perceived order in different sense modalities. Journal of Experimental Psychology, 62(5), 423-432.

Hoerl, C. (2009). Time and tense in perceptual experience. Philosopher's Imprint 9(12), 1-18.

Hoerl, C. (2013). A succession of feelings, in and of itself, is not a feeling of succession. Mind, 122(486), 373-417.

Holcombe, A. O. (2009). Seeing slow and seeing fast: two limits on perception. Trends in Cognitive Sciences, 13(5), 216-221.

Holcombe, A. (2015). The temporal organisation of perception. In J. Wagemans (Eds.), The Oxford Handbook of Perceptual Organization (pp. 820-839). Oxford: Oxford University Press.

Huemer, M. (2011). Sense-Data. In E. N. Zalta (Ed.), The Stanford Encyclopedia of Philosophy, URL=<https://plato.stanford.edu/archives/spr2017/entries/sense-data/>.

Husserl, E. (1928/1991). On the phenomenology of the consciousness of internal time (1893-1917), trans. J. Brough. Collected Works IV. Dordrecht: Kluwer Academic.

Kent, L. (2019). Duration perception versus perception duration: a proposed model for the consciously experienced moment. Timing \& Time Perception, 7(1), 1-14.

Kirman, J. H. (1974). Tactile apparent movement: the effects of number of stimulators. Journal of Experimental Psychology, 103(6), 1175-1180.

Kiverstein, J. (2010). Making sense of phenomenal unity: an intentional account of temporal experience. Royal Institute of Philosophy Supplement, 67, 155-181.

Kiverstein, J., \& Arstila, V. (2013). Time in mind. In H. Dyke \& A. Bardon (Eds.), A companion to the philosophy of time (pp. 444-469). Chichester: John Wiley \& Sons.

Koch, C. (2004). The quest for consciousness. A neurobiological approach. Englewood, CO: Roberts \& Company Publishers.

Kononowicz, T. W., \& van Rijn, H. (2015). Single trial beta oscillations index time estimation. Neuropsychologia, 75, 381-389.

Lackner, J. R., \& Teuber, H. L. (1973). Alterations in auditory fusion thresholds after cerebral injury in man. Neuropsychologia 11(4), 409-415.

Le Poidevin, R. (2007). The images of time: an essay on temporal representation. Oxford: Oxford University Press.

Lerner, Y., Honey, C. J., Silbert, L. J., \& Hasson, U. (2011). Topographic mapping of a hierarchy of temporal receptive windows using a narrated story. Journal of Neuroscience, 
31(8), 2906-2915.

Linares Gutierrez, D., Kübel, S., Giersch, A., Schmidt, S., Meissner, K., \& Wittmann, M. (2019). Meditation-induced states, vagal tone, and breathing activity are related to changes in auditory temporal integration. Behavioral Sciences, 9(5), 51.

Lloyd, D. (2004). Radiant Cool. Cambridge, MA: MIT Press.

Lloyd, D. (2012). Neural correlates of temporality: Default mode variability and temporal awareness. Consciousness and Cognition, 21(2), 695-703.

Lockwood, M. (2005). The labyrinth of time: introducing the universe. Oxford: Oxford University Press.

Longo, G., \& Montévil, M. (2011). Protention and retention in biological systems. Theory in Biosciences 130 (2), 107-117

Lotze, M., Wittmann, M., von Steinbüchel, N., Pöppel, E., \& Roenneberg, T. (1999). Daily rhythm of temporal resolution in the auditory system. Cortex 35(1), 89-100.

Madl, T., Franklin, S., Snaider, J., \& Faghihi, U. (2016). Continuity and the Flow of Time: A Cognitive Science Perspective. In B. Mölder, V. Arstila, \& P. Øhrstrøm (Eds.), Philosophy and Psychology of Time (pp. 135-160). Cham: Springer.

Marois, R., \& Ivanoff, J. (2005). Capacity limits of information processing in the brain. Trends in Cognitive Sciences, 9(6), 296-305.

Mates, J., Müller, U., Radil, T., \& Pöppel, E. (1994). Temporal integration in sensorimotor synchronization. Journal of Cognitive Neuroscience, 6(4), 332-340.

McAuley, J. D., Jones, M. R., Holub, S., Johnston, H. M., \& Miller, N. S. (2006). The time of our lives: life span development of timing and event tracking. Journal of Experimental Psychology: General, 135(3), 348-367.

McDowell, J. (1994). Mind and world. Cambridge, MA: Harvard University Press.

Mellor, D. (1998), Real Time II, Cambridge: Cambridge University Press.

Metzinger, T. (2004). Being no one. The self-model theory of subjectivity. Cambridge, MA: MIT Press.

Metzinger, T. (2008). Empirical perspectives from the self-model theory of subjectivity: a brief summary with examples. Chapter 18. In R. Banerjee \& B. K. Chakrabarti (Eds.), Progress in Brain Research, 168, (pp. 215-245). Amsterdam: Elsevier.

Mölder, B. (2014). How philosophical models explain time consciousness. Procedia - Social and Behavioral Sciences, 126, 48-57.

Montemayor, C. (2013). Minding time: a theoretical and philosophical approach to the psychology of time. Leiden: Brill. 
Montemayor, C., \& Wittmann, M. (2014). The varieties of presence: hierarchical levels of temporal integration. Timing \& Time Perception, 2(3), 325-338.

Nobre, A. C., \& van Ede, F. (2018). Anticipated moments: temporal structure in attention. Nature Reviews Neuroscience, 19(1), 34-48.

Northoff, G. (2014). Slow cortical potentials and „width of present“. In: Unlocking the brain Volume 2: Consciousness. Oxford: Oxford University Press.

Northoff, G. (2016). Slow cortical potentials and "inner time consciousness" - A neurophenomenal hypothesis about the "width of present". International Journal of Psychophysiology, 103, 174-184.

Nozick, R. (1981). Philosophical Explanations. Cambridge, MA: Harvard University Press.

Paul, D. (2010). Temporal experience. The Journal of Philosophy, 107(7), 333-359.

Park, H. D., Correia, S., Ducorps, A., \& Tallon-Baudry, C. (2014). Spontaneous fluctuations in neural responses to heartbeats predict visual detection. Nature Neuroscience, 17(4), 612618.

Pelczar, M. (2010). Must an Appearance of Succession Involve a Succession of Appearances? Philosophy and Phenomenological Research, 81(1),49-63.

Peters, M. (1989). The relationship between variability of intertap intervals and interval duration. Psychological Research, 51(1), 38-42.

Phillips, I. (2014). The temporal structure of experience. In V. Arstila, \& D. Lloyd (Eds.), Subjective time: the philosophy, psychology and neuroscience of temporality (pp. 139158). Cambridge, MA: MIT Press.

Pöppel, E. (1997). A hierarchical model of temporal perception. Trends in Cognitive Sciences $1(2), 56-61$.

Poggel, D. A., Treutwein, B., Calmanti, C., \& Strasburger, H. (2012). The Tölz Temporal Topography Study: Mapping the visual field across the life span. Part I: The topography of light detection and temporal-information processing. Attention, Perception \& Psychophysics, 74(6), 1114-1132.

Power, S. E. (2011). Temporal illusions-philosophical considerations. In A. Vatakis, A. Esposito, M. Giagkou, F. Cummins, \& G. Papadelis (Eds.), Multidisciplinary Aspects of Time and Time Perception (pp. 11-35). Berlin, Heidelberg: Springer.

Prosser, S., Experiencing Time, Oxford, Oxford University Press.

Ronconi, L., Oosterhof, N. N., Bonmassar, C., \& Melcher, D. (2017). Multiple oscillatory rhythms determine the temporal organization of perception. Proceedings of the National Academy of Sciences, 114(51), 13435-13440. 
Roselli, A. (2019). How long is now? A new perspective on the specious present. Disputatio, 10(49), 119-140.

Salmon, W. (1967). An "at-at" theory of causal influence. Philosophy of Science, 44(2), 215224.

Salomon, R., Ronchi, R., Dönz, J., Bello-Ruiz, J., Herbelin, B., Martet, R., Faivre, N., Schaller, K., \& Blanke, O. (2016). The insula mediates access to awareness of visual stimuli presented synchronously to the heartbeat. Journal of Neuroscience, 36(18), 5115-5127.

Schmidt, S., Jo, H. G., Wittmann, M., \& Hinterberger, T. (2016). 'Catching the waves'-slow cortical potentials as moderator of voluntary action. Neuroscience \& Biobehavioral Reviews, 68, 639-650.

Searle, J. (1983). Intentionality. Cambridge, MA: Cambridge University Press.

Sperling, G. (1960). The information available in brief visual presentations. Psychological Monographs: General and Applied, 74(11), 1-29.

Sider, T. (2001) Four dimensionalism. Oxford: Oxford University Press.

Stern, W. (1897). Psychische Präsenzzeit. Zeitschrift für Psychologie und die Physiologie der Sinnesorgane, 13, 325-349.

Stroud, J. M. (1955). The fine structure of psychological time. In H. Quastler (Eds.), Information theory in psychology: problems and methods (pp. 174-207). Glencoe, IL: Free Press.

Suddendorf, T., \& Coballis, M. C. (2007). The evolution of foresight: What is mental time travel, and is it unique to humans? Behavioral and Brain Sciences, 30(3), 299-351.

Szelag, E., Von Steinbüchel, N., Reiser, M., de Langen, E., \& Pöppel, E. (1995). Temporal constraints in processing of nonverbal rhythmic patterns. Acta Neurobiologiae Experimentalis, 56(1), 215-225.

Szpunar, K. K., Spreng, R. N., \& Schacter, D. L. (2014). A taxonomy of prospection: Introducing an organizational framework for future-oriented cognition. Proceedings of the National Academy of Sciences, 111(52), 18414-18421.

Szymaszek, A., Sereda, M., Pöppel, E., \& Szelag, E. (2009). Individual differences in the perception of temporal order: The effect of age and cognition. Cognitive Neuropsychology, 26(2), 135-147.

Teng, X., Tian, X., Doelling, K., \& Poeppel, D. (2017). Theta band oscillations reflect more than entrainment: behavioral and neural evidence demonstrates an active chunking process. European Journal of Neuroscience, DOI: 10.1111/ejn.13742.

Tschacher, W., Rees, G. M., \& Ramseyer, F. (2014). Nonverbal synchrony and affect in dyadic 
interactions. Frontiers in Psychology 5 (1323).

Tye, M., (2003), Consciousness and Persons. Cambridge Mass, The MIT Press.

Ulrich, R. (1987). Threshold models of temporal-order judgments evaluated by a ternary response task. Perception \& Psychophysics, 42(3), 224-239.

VanRullen, R., \& Koch, C. (2003). Is perception discrete or continuous? Trends in Cognitive Sciences, 7(5), 207-213.

VanRullen, R. (2016). Perceptual cycles. Trends in Cognitive Sciences, 20(10), 723-735.

van Wassenhove, V. (2009). Minding time - an amodal representational space for time perception. Philosophical Transactions of the Royal Society B, 364(1525), 1815-1830.

van Wassenhove, V. (2016). Temporal cognition and neural oscillations. Current Opinion in Behavioral Sciences, 8, 124-130.

van Wassenhove, V. (2017). Defining moments for conscious time and content. PsyCh Journal $6(2), 168-169$.

Varela, F. (1999). Present-time consciousness. Journal of Consciousness Studies, 6(2-3), 111140 .

Varela, F. J., Thompson, E., \& Rosch, E. (1991|2016). The embodied mind: Cognitive science and human experience. Cambridge, MA: MIT Press.

Vatakis, A., \& Spence, C. (2007). Crossmodal binding: Evaluating the "unity assumption" using audiovisual speech stimuli. Perception \& Psychophysics, 69(5), 744-756.

Vatakis, A., Navarra, J., Soto-Faraco, S., \& Spence, C. (2008). Audiovisual temporal adaptation of speech: temporal order versus simultaneity judgments. Experimental Brain Research, 185(3), 521-529.

Velichkovsky, B. M., Rothert, A., Kopf, M., Dornhöfer, S. M., \& Joos, M. (2002). Towards an express-diagnostics for level of processing and hazard perception. Transportation Research Part F: Traffic Psychology and Behaviour, 5(2), 145-156.

von Holst, E., \& Mittelstaedt, H. (1950). Das Reafferenzprinzip. Naturwissenschaften, 37(20), $464-476$.

Wacongne, C., Labyt, E., van Wassenhove, V., Bekinschtein, T., Naccache, L., \& Dehaene, S. (2011). Evidence for a hierarchy of predictions and prediction errors in human cortex. Proceedings of the National Academy of Sciences, 108(51), 20754-20759.

Wackermann, J. (2008). Measure of time: a meeting point of psychophysics and fundamental physics. Mind and Matter, 6(1), 9-50.

Wang, L., Lin, X., Zhou, B., Pöppel, E., \& Bao, Y. (2015). Subjective present: a window of temporal integration indexed by mismatch negativity. Cognitive Processing, 16(1), 131- 
135.

Wang, L., Bao, Y., Zhang, J., Lin, X., Yang, L., Pöppel, E., \& Zhou, B. (2016). Scanning the world in three seconds: Mismatch negativity as an indicator of temporal segmentation. PsyCh journal, 5(3), 170-176.

Ward, R., Duncan, J., \& Shapiro, K. (1996). The slow time-course of visual attention. Cognitive Psychology, 30(1), 79-109.

White, P. A. (2017). The Three-Second "Subjective Present": A Critical Review and a New Proposal. Psychological Bulletin, 143(7), 735-756.

White, P. A. (2018). Is conscious perception a series of discrete temporal frames? Consciousness and Cognition , 60, 98-126.

Wiener, M., \& Kanai, R. (2016). Frequency tuning for temporal perception and prediction. Current Opinion in Behavioral Sciences, 8, 1-6.

Wittmann, M., von Steinbüchel, N., \& Szelag, E. (2001). Hemispheric specialisation for selfpaced motor sequences. Cognitive Brain Research, 10(3), 341-344.

Wittmann, M. (2011). Moments in time. Frontiers in Integrative Neuroscience 5(66).

Wittmann, M. (2016). The duration of presence. In B. Mölder, V. Arstila, \& P. Øhrstrøm (Eds.), Philosophy and Psychology of Time (pp. 101-113). Cham: Springer.

Yarrow, K., \& Arnold, D. H. (2016). The timing of experiences: How far can we get with simple brain time models? In B. Mölder, V. Arstila, \& P. Øhrstrøm (Eds.), Philosophy and Psychology of Time (pp. 187-201). Cham: Springer.

Yi, R., Landes, R. D., \& Bickel, W. K. (2009). Novel models of intertemporal valuation: Past and future outcomes. Journal of Neuroscience, Psychology, and Economics, 2(2), 102111.

Zahavi, D. (2005). Subjectivity and selfhood: investigating the first-person perspective. Cambridge, MA: MIT Press. 